\title{
Acute effect of MitraClip implantation on mitral valve geometry in patients with functional mitral regurgitation: insights from three-dimensional transoesophageal echocardiography
}

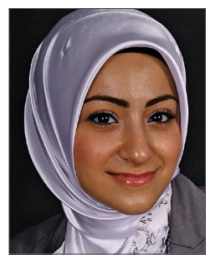

Ibtihal Al Amri' ${ }^{1}, \mathrm{MD}$; Philippe Debonnaire ${ }^{1,2}, \mathrm{MD}$; Frank van der Kley ${ }^{1}, \mathrm{MD}$; Martin J. Schalij ${ }^{1}, \mathrm{MD}, \mathrm{PhD}$; Jeroen J. Bax ${ }^{1}, \mathrm{MD}, \mathrm{PhD}$; Nina Ajmone Marsan ${ }^{1}, \mathrm{MD}, \mathrm{PhD}$; Victoria Delgado ${ }^{1 *}, \mathrm{MD}, \mathrm{PhD}$

1. Department of Cardiology, Leiden University Medical Center, Leiden, The Netherlands; 2. Department of Cardiology, Sint-Jan Hospital Bruges, Bruges, Belgium

I. Al Amri and P. Debonnaire contributed equally to this manuscript.

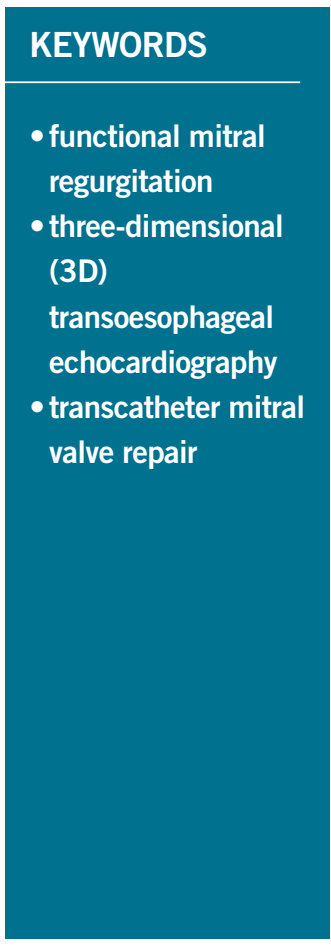

\begin{abstract}
Aims: Our aim was to evaluate the acute effects of transcatheter edge-to-edge mitral valve repair using the MitraClip device on mitral valve geometry in patients with functional mitral regurgitation (FMR).

Methods and results: Forty-two patients (age 73 years [IQ range 66.1-78.0], 55\% men, 62\% ischaemic FMR) with moderate-to-severe and severe FMR treated with the MitraClip were included. Threedimensional transoesophageal echocardiography was performed prior to and immediately after MitraClip implantation. Acute changes of mitral annular and leaflet geometry were assessed with dedicated mitral modelling software. FMR less than moderate grade was achieved in $36(86 \%)$ patients. After MitraClip implantation, the mitral annulus became more elliptical (ellipticity from $122 \pm 17 \%$ to $129 \pm 18 \%$; $\mathrm{p}=0.04$ ) with a non-significant reduction in anteroposterior diameter ( $33 \pm 6$ to $32 \pm 5 \mathrm{~mm}, \mathrm{p}=0.08$ ). The coaptation area increased from $350 \mathrm{~mm}^{2}$ (IQ range $289-493 \mathrm{~mm}^{2}$ ) to $434 \mathrm{~mm}^{2}$ (IQ range $328-523 \mathrm{~mm}^{2}, \mathrm{p}=0.008$ ). In particular, a larger part of the anterior mitral leaflet was included in the coaptation, leaving a smaller exposed anterior leaflet length of the A2 segment (from $27 \pm 6 \mathrm{~mm}$ to $25 \pm 5 \mathrm{~mm}, \mathrm{p}<0.05$ ) while the exposed length of the posterior leaflet ( $\mathrm{P} 2$ level) remained unchanged $(12 \pm 4 \mathrm{~mm}$ pre- vs. $13 \pm 4 \mathrm{~mm}$ post-repair, $\mathrm{p}=0.15)$. There was no change in total leaflet area $\left(1,811 \pm 582 \mathrm{~mm}^{2}\right.$ pre- vs. $1,870 \pm 506 \mathrm{~mm}^{2}$ post-repair, $\mathrm{p}=0.18$ ). Annular height to intercommissural width ratio and tenting volume remained unchanged, suggesting no increase in leaflet stress.
\end{abstract}

Conclusions: The MitraClip device affects MV geometry in FMR patients by increasing mitral annular ellipticity and coaptation area.

\footnotetext{
*Corresponding author: Department of Cardiology, Leiden University Medical Center, Albinusdreef 2, 2333 ZA Leiden, The Netherlands. E-mail:v.delgado@lumc.nl
} 


\section{Abbreviations}

$\begin{array}{ll}\text { FMR } & \text { functional mitral regurgitation } \\ \text { LV } & \text { left ventricle } \\ \text { MVQ } & \text { mitral valve quantification } \\ \text { TEE } & \text { transoesophageal echocardiography } \\ \text { TTE } & \text { transthoracic echocardiography }\end{array}$

\section{Introduction}

Functional mitral regurgitation (FMR) is common in heart failure patients and is associated with poor clinical outcomes ${ }^{1-4}$. Surgical mitral valve repair has proven to be beneficial, providing significant improvement in symptoms and left ventricular (LV) function ${ }^{5,6}$. However, many patients with significant FMR are not referred for or are denied surgical intervention due to a high operative risk, related to advanced age and the presence of associated comorbidities ${ }^{7}$. Several minimally invasive and transcatheterbased mitral valve repair techniques provide feasible alternative treatment options to conventional valve surgery for patients with a high operative risk. The transcatheter edge-to-edge mitral valve repair technique using the MitraClip $^{\circledR}$ system (Abbott Vascular Structural Heart, Menlo Park, CA, USA) is designed to grasp the mitral valve leaflets at the middle scallops, creating a double orifice valve during diastole and maintaining closer apposition of the leaflets during systole to reduce the regurgitant volume. With more than 17,000 patients treated worldwide, the MitraClip device has been demonstrated to be a feasible and safe procedure, also in patients with FMR, and to improve symptoms ${ }^{8,9}$. The effect of the MitraClip device on the geometry and function of the mitral valve, however, remains largely unexplored. Three-dimensional (3D) transoesophageal (TEE) echocardiography allows accurate measurements of mitral valve geometry ${ }^{10}$. Accordingly, the present study aimed to evaluate the acute effects of transcatheter edgeto-edge repair on mitral annular geometry and leaflet coaptation zones of patients with FMR using 3D TEE.

\section{Methods}

\section{PATIENT POPULATION AND DATA COLLECTION}

A total of 59 patients were treated with the MitraClip device at the Leiden University Medical Centre between January 2012 and July 2014. Thorough clinical and echocardiographic evaluation was performed prior to the procedure by an interdisciplinary team of cardiac surgeons and cardiologists. Patients had symptomatic moderate-to-severe or severe mitral regurgitation and were at high risk for conventional surgical mitral valve repair, defined by a logistic EuroSCORE $>20 \%$ or the presence of specific risk factors associated with excessive morbidity and mortality. Evaluation of clinical symptoms included assessment of functional capacity according to the New York Heart Association (NYHA) functional class and the six-minute walking distance test. Furthermore, a quality of life assessment was performed using the Minnesota Living With Heart Failure ${ }^{\circledR}$ questionnaire ${ }^{11}$. Transthoracic echocardiographic (TTE) assessment and TEE assessment were routinely performed before the intervention to assess left ventricular
(LV) dimensions and function, mitral valve morphology and mitral regurgitation grade, and evaluation of factors that may contraindicate the procedure ${ }^{12}$. The procedure was guided with 3D TEE allowing acquisition of $3 \mathrm{D}$ data of the mitral valve. In the current analysis, only patients with FMR and sufficient quality of periprocedural 3D TEE data allowing geometrical analysis of the mitral valve were included $(n=42)$.

\section{TWO-DIMENSIONAL (2D) TRANSTHORACIC ECHOCARDIOGRAPHIC EVALUATION}

Pre-procedural TTE was performed using commercially available ultrasound systems (E9 or Vivid 7; GE Norway, Horten, Norway) equipped with an M5S transducer, and 2D, M-mode and Doppler data were acquired with the patient in the left lateral decubitus position. LV dimensions and function were assessed according to the recommendations of the American Society of Echocardiography and the European Association of Echocardiography ${ }^{13}$. From the apical 4- and 2-chamber views, the LV end-diastolic and end-systolic volumes and LV ejection fraction were measured according to the biplane Simpson's method. LV diameters were assessed at end-diastole and end-systole from the parasternal long-axis view or M-mode recordings. From the apical 2-, 3- and 4-chamber views, colour and continuous wave Doppler data of the mitral valve were acquired, and mitral regurgitation was quantitatively determined by the proximal isovelocity surface area method and by measuring the vena contracta according to current guidelines ${ }^{14}$.

\section{D TRANSOESOPHAGEAL ECHOCARDIOGRAPHIC DATA ACQUISITION AND EVALUATION}

TEE was performed during the procedure using a commercially available ultrasound system (iE33; Philips Medical Systems, Andover, MA, USA) equipped with a fully sampled matrix-array TEE transducer (X7-2t Live 3D-TEE transducer, iE33; Philips Medical Systems) capable of acquiring both 2D and 3D images to guide implantation of the MitraClip device and to assess acute procedural success. Three-dimensional images were acquired during the intervention before and directly after implantation of the MitraClip device, using multi-beat (7-14 beats) full-volume or one-beat 3D-zoom acquisitions encompassing a pyramid volume. The multi-beat full-volume images were acquired during respiratory breath hold whenever possible to avoid stitch artefacts. In patients with atrial fibrillation, one-beat 3D-zoom acquisitions with the sector adjusted to include the mitral valve were performed. Furthermore, special care was taken to stabilise the probe during 3D data acquisition. All images were digitally stored for off-line analysis with the MVQ software (QLAB Cardiac 3DQ v.10.0; Philips Medical Systems), which allows semi-automated $3 \mathrm{D}$ quantification of the mitral valve geometry ${ }^{10}$. From 3D fullvolume or zoomed data sets of the mitral valve, the software displays three orthogonal multiplanar reformation planes of the mitral valve at end-systole. The planes are manually aligned across the mitral annulus in a selected end-systolic frame to obtain bicommissural, outflow tract and short-axis views of the mitral valve. 
The bicommissural view was used to indicate the anterolateral and posteromedial points of the mitral annulus, whereas the outflow tract view was used to define the anterior and posterior points of the mitral annulus, the aortic annulus and the mitral leaflet coaptation point. The mitral leaflet commissural points were set on the short-axis plane, and the mitral leaflets and coaptation length were traced on multiple cross-sections (18-30) in the outflow tract view, orthogonal to the intercommissural direction. The 3D-rendered surgical en face view was used to identify the coaptation point correctly (Figure 1). Subsequently, the software automatically creates a $3 \mathrm{D}$ model of the mitral valve geometry and various measurements can be derived.

The measurements of the mitral valve with the MVQ software were performed at end-systole and included anteroposterior and intercommissural annular diameters and area, and leaflet lengths, angles and areas. Mitral annular ellipticity was calculated as the ratio between the anteroposterior annular diameter and the intercommisural diameter. Furthermore, to assess the effect of the MitraClip on mitral leaflet coaptation, the coaptation length at the middle scallops (A2-P2) was measured and the coaptation area was calculated by subtracting the exposed area of the anterior and posterior mitral

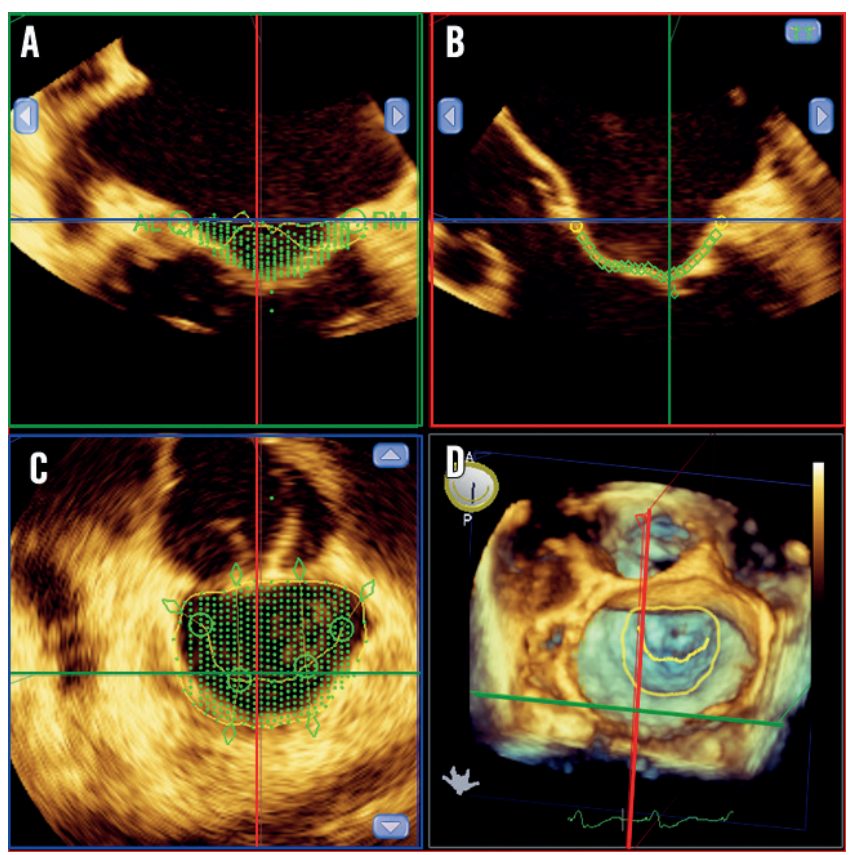

Figure 1. Identification of $3 D$ landmarks on multiplanar reformation planes using Mitral Valve Quantification (MVQ) software. Using the multiplanar reformation planes, the MVQ software identifies the landmark points of the mitral annulus. The anterior, posterior, anterolateral and posteromedial points of the mitral annulus are identified on the 2-and 3-chamber views. The en face view provides the cross-sectional area of the mitral annulus and simultaneously the $3 D$ full volume of the mitral valve can be visualised. A) Identification of leaflet insertion points. B) Tracing the mitral leaflets and marking the leaflet coaptation point. C) Tracing the coaptation line. D) 3D surgical view of the mitral valve with the manually traced lines visible. leaflets (i.e., the area without the coapting part of the leaflets) from the total area of the anterior and posterior leaflets (i.e., the area including the coapting part of the leaflets). Moreover, the effect of the MitraClip on leaflet stress was analysed by assessing the annular height to intercommissural width ratio and the non-planarity angle ${ }^{15}$. The non-planarity angle was determined as the angle between the anterior and posterior leaflet hinge points of the annulus to the centre of the intercommissural line. Additionally, tenting height at the A2-P2 level, tenting volume and the angle between the mitral annulus and aortic annulus were measured. Three-dimensional TEE data were analysed by two experienced observers. The intra-observer reproducibility of the anteroposterior and intercommissural diameter measurements was good, with respective intraclass correlation coefficients of 0.865 and 0.883 as well as the inter-observer reproducibility with respective intraclass correlation coefficients of 0.755 and 0.855 . Intraclass correlation coefficients for overall (total) leaflet area were 0.903 (intra-observer) and 0.947 (inter-observer) ${ }^{16}$. For exposed leaflet area measurements, the intraclass correlation coefficients were 0.955 and 0.947 for intra-observer and inter-observer reproducibility, respectively. An example of mitral geometry measurements performed before and after MitraClip implantation in a patient using MVQ software is displayed in Figure 2.

\section{PROCEDURAL TECHNIQUE}

The transcatheter edge-to-edge mitral valve intervention was performed as previously described using the MitraClip system and guided by fluoroscopy and $2 \mathrm{D}$ and $3 \mathrm{D} \mathrm{TEE}^{12,17}$. In brief, after transseptal punction, the clip delivery system was advanced into the left atrium and positioned above the mitral valve plane over the origin of the regurgitant jet. The device was oriented perpendicular to the line of coaptation and the system was advanced into the LV with the arms slightly opened. After ensuring good alignment of the device (just below the regurgitant orifice on the TEE bicommissural view of the mitral valve) and simultaneously visualising the arms of the device opened in the perpendicular TEE view (120-150 ${ }^{\circ}$, or LV outflow tract view), the system was pulled back to grasp the mitral leaflets in the arms of the clip and create a double orifice valve. The grade of MR was assessed during the procedure using colour and continuous wave Doppler echocardiography. Procedural success was defined as a reduction of MR to less than moderate grade. If needed, a second clip was placed to ensure less than moderate grade MR without significant stenosis.

\section{STATISTICAL ANALYSIS}

Distribution of the continuous data was tested by the KolmogorovSmirnov one-sample test and the Shapiro-Wilk test. Normally distributed continuous variables are presented as mean \pm standard deviation, whereas non-normally distributed variables are presented as median and interquartile range. Categorical variables are expressed as frequencies and percentages. Comparisons of mitral valve geometry pre- and post-procedure were performed using the paired Student's t-test for normally distributed variables and the Wilcoxon signed-rank test for non-normally distributed variables. 

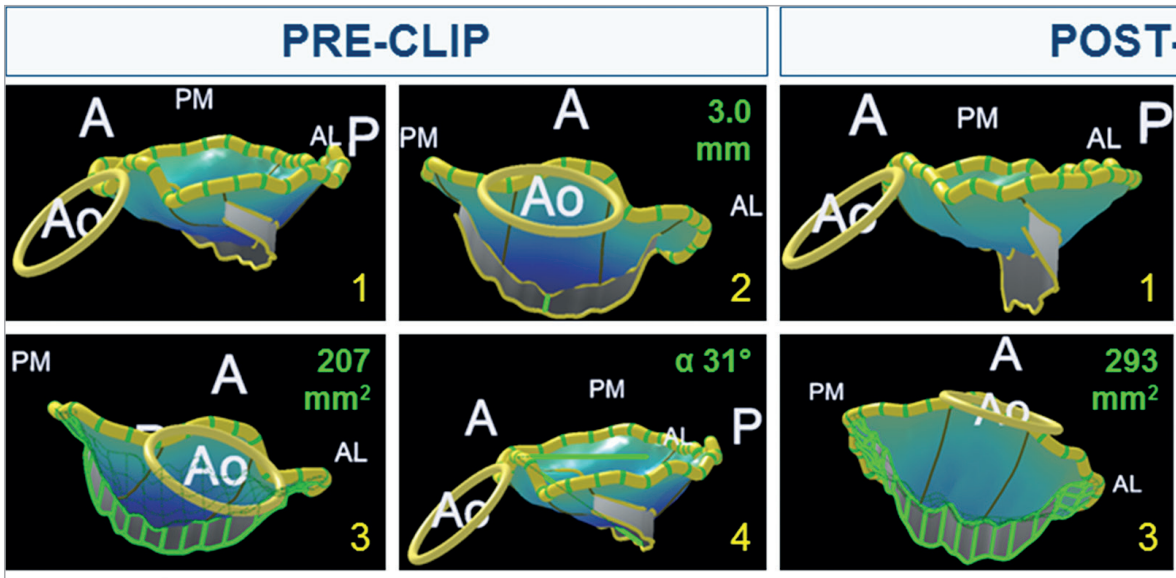

\section{-CLIP}
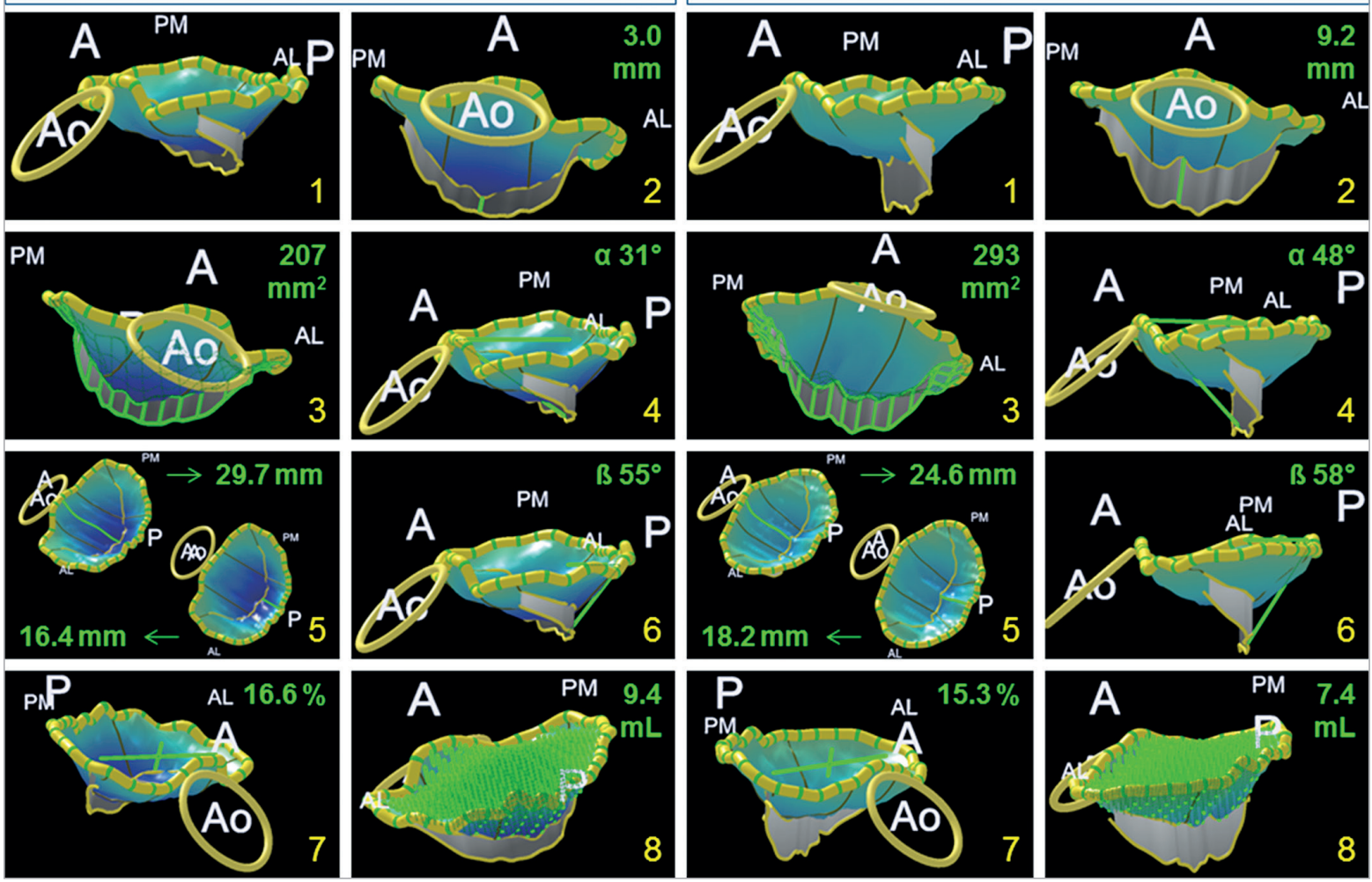

Figure 2. Example of changes in mitral valve geometry in a patient before and after MitraClip implantation with 3D model. 1) 3D model of the mitral valve. 2) Coaptation length at the A2-P2 level pre-and post-MitraClip implantation. 3) Coaptation area pre-and post-MitraClip implantation. 4) Angle between anterior leaflet and mitral annulus aorta pre-and post-MitraClip implantation. 5) Length of the anterior (A) and posterior $(P)$ leaflet at the A2 and P2 level, respectively, pre-and post-MitraClip implantation. 6) Angle between posterior leaflet and mitral annulus pre- and post-MitraClip implantation. 7) Ellipticity. 8) Tenting volume. A: anterior; AL: anterolateral; Ao: aorta; P: posterior; PM: posteromedial

All statistical tests were two-tailed and a $\mathrm{p}<0.05$ was considered statistically significant. Statistical analysis was performed using SPSS for Windows, Version 20.0.0 (IBM Corp., Armonk, NY, USA).

\section{Results}

\section{BASELINE CHARACTERISTICS}

Baseline demographic, clinical and echocardiographic characteristics of the patients are listed in Table 1. Moderate-to-severe FMR was observed in $48 \%$ of patients and severe FMR in $52 \%$. Ischaemic heart failure was the most frequent underlying aetiology of heart failure $(62 \%)$.

\section{CHANGES IN 3D MITRAL VALVE GEOMETRY AFTER MITRACLIP} FMR reduction to less than moderate grade was achieved in 36 (86\%) patients. End-systolic changes of mitral valve geometry post MitraClip implantation are presented in Table 2. After the procedure, the mitral annulus became more elliptical (increase in ellipticity from $122 \pm 17 \%$ to $129 \pm 17 \%, \mathrm{p}<0.05)$ and there was an increase in both the anterior (from $27 \pm 7^{\circ}$ to $34 \pm 8^{\circ}, \mathrm{p}<0.001$ ) and posterior (from $49 \pm 14^{\circ}$ to $56 \pm 10^{\circ}, \mathrm{p}=0.02$ ) mitral leaflet angles (Figure 3 ). The anteroposterior mitral annular diameter decreased from $33 \pm 6 \mathrm{~mm}$ to $32 \pm 5 \mathrm{~mm}$, although this change was not statistically significant $(\mathrm{p}=0.08)$. Furthermore, an increase in both coaptation length at the A2-P2 level (from 5.0 $\pm 1.12 \mathrm{~mm}$ to $5.3 \pm 0.87 \mathrm{~mm}, \mathrm{p}<0.001$ ) and total coaptation area (from $215 \mathrm{~mm}^{2}$

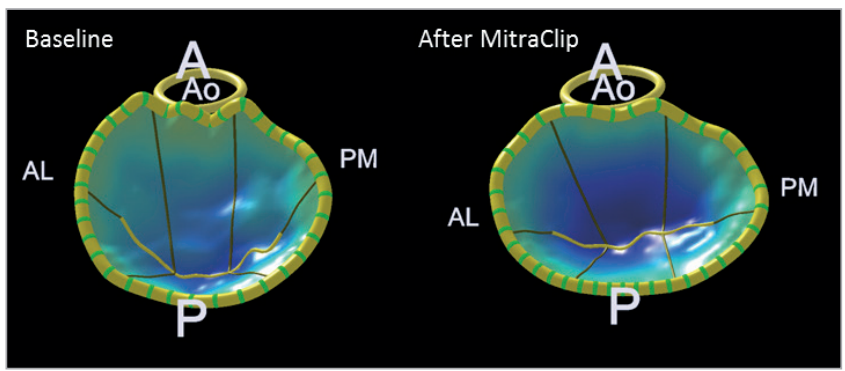

Figure 3. 3D modelling of the acute effect of the MitraClip device on mitral valve geometry. After MitraClip implantation, the anteroposterior diameter reduced from $36.5 \mathrm{~mm}$ to $33.5 \mathrm{~mm}$, while the intercommissural diameter slightly increased from $41.5 \mathrm{~mm}$ to $43.7 \mathrm{~mm}$ and the ellipticity increased consequently from $113.7 \%$ to 130.7\%. A: anterior; AL: anterolateral; Ao: aorta; P: posterior; PM: posteromedial 
Table 1. Baseline demographic, clinical and echocardiographic patient characteristics.

\begin{tabular}{|c|c|}
\hline & $n=42$ \\
\hline Male gender, n (\%) & $23(55)$ \\
\hline Age, yrs & $72.8[66.1-78.0]$ \\
\hline Hypertension, n (\%) & $18(43)$ \\
\hline Hypercholesterolaemia, n (\%) & $17(42)$ \\
\hline Positive family history of CVD, $\mathrm{n}(\%)$ & $8(20)$ \\
\hline (Ex-) smoker, n (\%) & $21(50)$ \\
\hline Diabetes mellitus, n (\%) & $16(38)$ \\
\hline COPD, n (\%) & $6(14)$ \\
\hline Peripheral vascular disease, $\mathrm{n}(\%)$ & $11(26)$ \\
\hline Prior stroke, $\mathrm{n}(\%)$ & $5(12)$ \\
\hline Ischaemic cardiomyopathy, n (\%) & $26(62)$ \\
\hline Prior myocardial infarction, n (\%) & $22(52)$ \\
\hline \multicolumn{2}{|l|}{ Location of myocardial infarction, $\mathrm{n}(\%)$} \\
\hline Anterior & $11(50)$ \\
\hline Inferior & $6(27)$ \\
\hline Anteroseptal & $2(9)$ \\
\hline Posterolateral & $2(9)$ \\
\hline Posterior & $1(5)$ \\
\hline NYHA Class III-IV, n (\%) & $35(83)$ \\
\hline Logistic EuroSCORE (\%) & $17.7[10.9-27.4]$ \\
\hline Glomerular filtration rate $\left(\mathrm{ml} / \mathrm{min} / 1.73 \mathrm{~m}^{2}\right)$ & $49.3[26.4-75.0]$ \\
\hline Sinus rhythm, $\mathrm{n}(\%)$ & $14(33)$ \\
\hline CRT, n (\%) & $16(38)$ \\
\hline \multicolumn{2}{|l|}{ Medication, n (\%) } \\
\hline Beta-blockers & $34(81)$ \\
\hline ACE/angiotensin receptor II inhibitors & $28(78)$ \\
\hline Diuretics & $37(88)$ \\
\hline Digoxin & $11(26)$ \\
\hline Statin & $29(69)$ \\
\hline Calcium antagonist & $4(10)$ \\
\hline Aspirin & $13(31)$ \\
\hline Anticoagulants & $40(95)$ \\
\hline LV end-diastolic diameter $(\mathrm{mm})$ & $63.2 \pm 9.3$ \\
\hline LV end-systolic diameter (mm) & $52.7 \pm 13.5$ \\
\hline LV end-diastolic volume (ml) & 176.5 [133.8-243.8] \\
\hline LV end-systolic volume (ml) & $118.5[82.5-163.8]$ \\
\hline LV ejection fraction (\%) & $33.7 \pm 10.3$ \\
\hline \multicolumn{2}{|l|}{ Mitral regurgitation } \\
\hline Grade 3 & $20(48)$ \\
\hline Grade 4 & $22(52)$ \\
\hline \multicolumn{2}{|l|}{ Number of clips implanted } \\
\hline 1 clip & $24(57)$ \\
\hline 2 clips & $15(36)$ \\
\hline 3 clips & $1(2)$ \\
\hline 4 clips & $2(5)$ \\
\hline \multicolumn{2}{|c|}{$\begin{array}{l}\text { ACE: angiotensin-converting enzyme; COPD: chronic obstructive } \\
\text { pulmonary disease; CRT: cardiac resynchronisation therapy; } \\
\text { CVD: cardiovascular disease; LV: left ventricular; NYHA: New York Heart } \\
\text { Association }\end{array}$} \\
\hline
\end{tabular}

[IQ range 164-264] to $281 \mathrm{~mm}^{2}$ [IQ range 238-386], $\mathrm{p}=0.005$ ) was observed (Figure 4). In addition, the exposed length of the anterior mitral leaflet (i.e., excluding the coapting part of the leaflet) at the A2 level (from $27 \pm 6 \mathrm{~mm}$ to $25 \pm 5 \mathrm{~mm}, \mathrm{p}=0.03$ ) and the exposed anterior leaflet area (from $795 \pm 277 \mathrm{~mm}^{2}$ to $730 \pm 222 \mathrm{~mm}^{2}, \mathrm{p}=0.04$ ) decreased while the posterior leaflet length at the P2 level and total leaflet area remained unchanged, indicating that the improvement in leaflet coaptation was due to a larger area of the anterior mitral leaflet involved in the coaptation (Figure 5). The annular height to intercommissural width ratio, non-planarity angle and tenting volume remained unchanged after MitraClip therapy, suggesting no increase in leaflet stress.

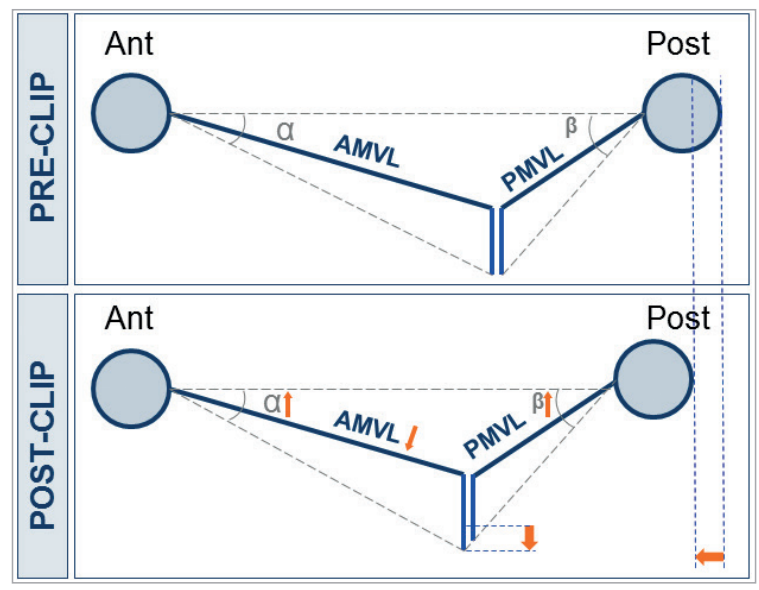

Figure 4. Schematic overview of acute effect of MitraClip device on mitral valve geometry showing that the MitraClip device leads to a decrease in exposed anterior leaflet length (AMVL) at the A2 level. Furthermore, the anteroposterior diameter tends to reduce with corresponding increases in the anterior and posterior mitral leaflet angles ( $\alpha$ and $\beta)$. AMVL: anterior mitral valve leaflet; PMVL: posterior mitral valve leaflet

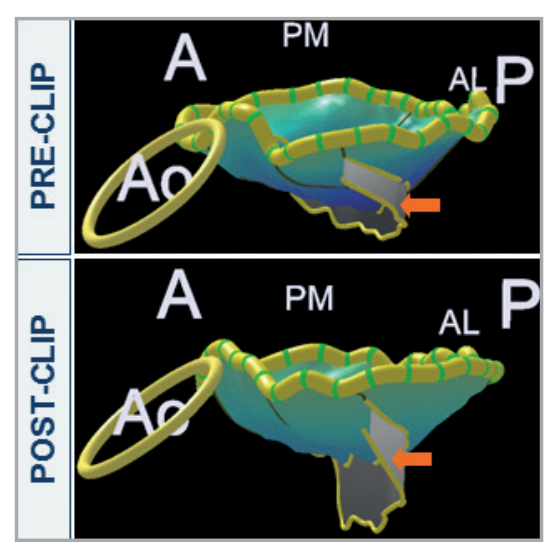

Figure 5. 3D overview of acute effect of MitraClip therapy on mitral valve geometry showing an increase in coaptation area. The long-axis view of the 3D model is shown at baseline and after MitraClip implantation with the arrow pointing to the area of coaptation. A: anterior; AL: anterolateral; Ao: aorta; P: posterior; PM: posteromedial 
Table 2. Echocardiographic mitral valve geometry parameters pre- and post-MitraClip implantation measured in end systole with 3D transoesophageal echocardiography.

\begin{tabular}{|c|c|c|c|}
\hline & Pre-MitraClip & Post-MitraClip & $p$-value \\
\hline \multicolumn{4}{|l|}{ Annulus } \\
\hline Anteroposterior diameter (mm) & $33.2 \pm 6.2$ & $32.1 \pm 5.3$ & 0.08 \\
\hline Intercommissural diameter (mm) & $39.9 \pm 6.4$ & $41.1 \pm 6.5$ & 0.15 \\
\hline Ellipticity (\%) & $121.8 \pm 17.3$ & $129.4 \pm 18.4$ & 0.04 \\
\hline Circumference (mm) & $124.5 \pm 19$ & $124.8 \pm 17.4$ & 0.88 \\
\hline Annular area $\left(\mathrm{mm}^{2}\right)$ & $1,178.0 \pm 380.2$ & $1,170.7 \pm 326.1$ & 0.81 \\
\hline Annular height (mm) & $5.5 \pm 1.9$ & $5.7 \pm 1.9$ & 0.62 \\
\hline Annular height to intercommissural width ratio (\%) & $20.2 \pm 13.8$ & $18.3 \pm 6.3$ & 0.41 \\
\hline \multicolumn{4}{|l|}{ Leaflets } \\
\hline Anterior leaflet length exposed A2 segment $(\mathrm{mm})^{*}$ & $27.2 \pm 5.5$ & $25.4 \pm 5.0$ & 0.03 \\
\hline Posterior leaflet length exposed P2 segment $(\mathrm{mm})^{*}$ & $11.6 \pm 4.1$ & $12.5 \pm 4.3$ & 0.15 \\
\hline Anterior leaflet exposed area $\left(\mathrm{mm}^{2}\right)^{*}$ & $795.4 \pm 277.0$ & $729.8 \pm 222.0$ & 0.04 \\
\hline Posterior leaflet exposed area $\left(\mathrm{mm}^{2}\right)^{*}$ & $636.9 \pm 257.0$ & $666.3 \pm 227.5$ & 0.32 \\
\hline Total leaflet area $\left(\mathrm{mm}^{2}\right)$ & $1,811.2 \pm 582.2$ & $1,870.3 \pm 505.5$ & 0.18 \\
\hline Anterior leaflet angle $\left({ }^{\circ}\right)$ & $27.1 \pm 7.4$ & $33.6 \pm 7.9$ & $<0.001$ \\
\hline Posterior leaflet angle $\left(^{\circ}\right)$ & $49.0 \pm 13.6$ & $56.1 \pm 10.3$ & 0.02 \\
\hline Aortomitral angle $\left({ }^{\circ}\right)$ & $134.8 \pm 11.2$ & $133.0 \pm 11.3$ & 0.39 \\
\hline Non-planarity angle $\left(^{\circ}\right)$ & $122.6 \pm 18.3$ & $123.3 \pm 18.4$ & 0.82 \\
\hline Tenting height A2-P2 (mm) & $8.1 \pm 3.4$ & $8.2 \pm 3.0$ & 0.65 \\
\hline Tenting volume $(\mathrm{mL})$ & $2.9[1.7-4.5]$ & $3.3[2.5-4.5]$ & 0.80 \\
\hline \multicolumn{4}{|l|}{ Coaptation } \\
\hline Coaptation length A2-P2 (mm) & $5.0 \pm 1.12$ & $5.3 \pm 0.87$ & $<0.001$ \\
\hline Coaptation area $\left(\mathrm{mm}^{2}\right)$ & 349.6 [289.0-492.8] & $433.8[327.6-522.7]$ & 0.008 \\
\hline
\end{tabular}

\section{Discussion}

The results of this study demonstrate that the percutaneous edgeto-edge mitral valve repair procedure using the MitraClip device directly affects mitral valve geometry. By grasping the anterior and posterior leaflets, the coaptation length and area of the mitral leaflets significantly increase in end-systole, with a large proportion of the anterior mitral leaflet grasped and included within the device arm while the posterior mitral annulus is anteriorly approximated.

Few studies have assessed the effect of surgical annuloplasty on mitral valve anatomy using 3D TEE. Greenhouse et al used intraoperative 3D TEE to examine the regional effects of surgical mitral annuloplasty on annular geometry and leaflet coaptation zones in patients with $\mathrm{FMR}^{18}$. A significant increase in mitral leaflet coaptation length after band annuloplasty was observed, particularly at the middle scallops of the anterior mitral leaflet $(2.9 \pm 2.6 \mathrm{~mm}$ at baseline vs $5.5 \pm 2.5 \mathrm{~mm}$ post surgery, $\mathrm{p}<0.01)$. The posterior annulus was displaced anteriorly, leading to an increase of coaptation surface of the anterior leaflet and correction of the mitral regurgitation. Our findings are in agreement with this concept by showing that the exposed length and area of the anterior leaflet at the central scallop (i.e., the anterior leaflet length and area without the coapting part) decreased. These changes were not accompanied by changes in the total mitral leaflet area, indicating inclusion of a large proportion of the anterior leaflet into the area of coaptation. Therefore, implantation of a MitraClip device seems to affect mitral coaptation geometry similarly to surgical mitral annuloplasty, albeit through a different mechanism.

In patients with FMR treated with the MitraClip device, Schmidt et al reported significant reductions of the mitral annular area (mean difference $0.39 \pm 0.49 \mathrm{~cm}^{2}, \mathrm{p}<0.001$ ) and anteroposterior annular diameter (mean difference $0.28 \pm 0.32 \mathrm{~cm}, \mathrm{p}<0.001$ ) as well as a significant reduction in tenting area (mean difference $\left.0.39 \pm 0.49 \mathrm{~cm}^{2}, \mathrm{p}<0.001\right)^{19}$. The disparate results of the study by Schmidt et al and the present study may be explained by the different post-processing analysis. While Schmidt et al performed the measurements on the orthogonal multiplanar reformations of the $3 \mathrm{D}$ TEE volume set, in the present study the measurements were performed on $3 \mathrm{D}$ models that permit assessment of the saddle shape of the mitral annulus. However, the current analysis did show a change in the shape of the mitral annulus with an increase in annular ellipticity and slight decrease (not statistically significant) in anteroposterior diameter, which is consistent 
with previous reports ${ }^{19-21}$. Recently, Schueler et al showed that patients with FMR showed significant decreases in the anteroposterior diameter of the mitral annulus (from $4.0 \pm 0.6 \mathrm{~cm}$ to $3.6 \pm 0.6 \mathrm{~cm}, \mathrm{p}<0.001$ ), 3D mitral annulus area (from $14.4 \pm 3.9 \mathrm{~cm}^{2}$ to $12.9 \pm 3.4 \mathrm{~cm}^{2}, \mathrm{p}<0.001$ ) and mitral valve sphericity index (from $0.9 \pm 0.1$ to $0.8 \pm 0.1, \mathrm{p}<0.001$ ), whereas the intercommisural diameter remained unchanged ${ }^{21}$. Interestingly, these changes were not observed in patients with degenerative mitral regurgitation. Furthermore, patients in whom the anteroposterior diameter acutely reduced $\geq 6.4 \%$ had superior clinical response to MitraClip therapy after six months of follow-up compared with patients showing less acute annulus diameter reduction. However, an acute reduction in the anteroposterior diameter after MitraClip therapy would indicate significant traction on the mitral leaflets to reduce the distance between the anterior and posterior annulus. This high leaflet stress could affect the durability of the procedure. To assess leaflet stress, we analysed the annular height to intercommissural width ratio. It has been shown that mechanical leaflet stress is minimal when the saddle shape of the mitral annulus is preserved (i.e., annular height to intercommissural width ratio $<15-20 \%)^{15}$. In the present study, the annular height to intercommissural width ratio did not significantly reduce after MitraClip implantation, suggesting no acute increase in leaflet stress.

Understanding the effects of the MitraClip on the geometry of the mitral valve will eventually help to identify patients who will benefit most from this procedure. Currently available 3D TEE data post-processing software has provided further insight into how this device affects the geometry of the mitral valve and which changes are associated with sustained reduction in FMR at midterm follow-up ${ }^{21}$. Additional advances in post-processing software or development of novel computational simulation software ${ }^{22}$ may help to improve the implantation strategy along with new developments of the device that may improve the acute and long-term outcomes of this technique.

\section{Limitations}

There are several limitations that should be acknowledged. First, the study population was rather small. By recording both the pre- and post-procedural views during anaesthesia we aimed to create a similar haemodynamic status for the pre- and post-procedural measurements of mitral annular geometry. However, the effects of the anaesthetics on patients' haemodynamic status must be considered. Furthermore, the clips caused shadowing artefacts and limited the evaluation of the coaptation point. By tracing the coaptation point in the body of the MitraClip after the procedure, which is the point where the leaflets are grasped by the clip, we aimed to reduce the effect of the artefacts on the outcomes.

\section{Conclusions}

Percutaneous MitraClip therapy affects mitral valve geometry in FMR patients by increasing coaptation length and area due to a larger contribution of the anterior mitral leaflet to coaptation after the procedure.

\section{Impact on daily practice}

Evaluating the effects of MitraClip on 3-dimensional mitral valve geometry is important to understand its therapeutic efficacy and durability. The present study showed that MitraClip increases the coaptation length and area due to a larger contribution of the anterior mitral leaflet into the coaptation. Furthermore, the anteroposterior diameter tends to reduce with corresponding increases in the anterior and posterior mitral leaflet angles. Subsequent iterations of the device or development of newer systems may consider these findings to improve the efficacy of the repair. Although the effects of these geometrical changes on long-term durability were not evaluated in the present study, future investigations may shed light on this topic and help in the design of novel devices.

\section{Funding}

The Department of Cardiology of the Leiden University Medical Center has received research grants from GE Healthcare, St. Jude Medical, Medtronic, Boston Scientific, Edwards Lifesciences and Biotronik.

\section{Conflict of interest statement}

V. Delgado has received consulting fees from St. Jude Medical and Medtronic and speaker's fees from Abbott Vascular. P. Debonnaire is supported by a Sadra Medical Research Grant (Boston Scientific), holds a European Association of Cardiovascular Imaging Research Grant for 2013, receives speaker's fees from Abbott Vascular and is a faculty member of Abbott Vascular Crossroads. No specific financial support for this work is involved. The other authors have no conflicts of interest to declare.

\section{References}

1. Bursi F, Enriquez-Sarano M, Nkomo VT, Jacobsen SJ, Weston SA, Meverden RA, Roger VL. Heart failure and death after myocardial infarction in the community: the emerging role of mitral regurgitation. Circulation. 2005;111:295-301.

2. Trichon BH, Felker GM, Shaw LK, Cabell CH, O'Connor CM. Relation of frequency and severity of mitral regurgitation to survival among patients with left ventricular systolic dysfunction and heart failure. Am J Cardiol. 2003;91:538-43.

3. Bursi F, Barbieri A, Grigioni F, Reggianini L, Zanasi V, Leuzzi C, Ricci C, Piovaccari G, Branzi A, Modena MG. Prognostic implications of functional mitral regurgitation according to the severity of the underlying chronic heart failure: a long-term outcome study. Eur J Heart Fail. 2010;12:382-8.

4. Rossi A, Dini FL, Faggiano P, Agricola E, Cicoira M, Frattini S, Simioniuc A, Gullace M, Ghio S, Enriquez-Sarano M, Temporelli PL. Independent prognostic value of functional mitral regurgitation in patients with heart failure. A quantitative analysis of 1256 patients with ischaemic and non-ischaemic dilated cardiomyopathy. Heart. 2011;97:1675-80.

5. Bax JJ, Braun J, Somer ST, Klautz R, Holman ER, Versteegh MI, Boersma E, Schalij MJ, van der Wall EE, Dion RA. 
Restrictive annuloplasty and coronary revascularization in ischemic mitral regurgitation results in reverse left ventricular remodeling. Circulation. 2004;110(11 Suppl 1):II103-8.

6. Westenberg JJ, van der Geest RJ, Lamb HJ, Versteegh MI, Braun J, Doornbos J, de Roos A, van der Wall EE, Dion RA, Reiber JH, Bax JJ. MRI to evaluate left atrial and ventricular reverse remodeling after restrictive mitral annuloplasty in dilated cardiomyopathy. Circulation. 2005;112:I437-42.

7. Mirabel M, Iung B, Baron G, Messika-Zeitoun D, Detaint D, Vanoverschelde JL, Butchart EG, Ravaud P, Vahanian A. What are the characteristics of patients with severe, symptomatic, mitral regurgitation who are denied surgery? Eur Heart J. 2007;28:1358-65.

8. Whitlow PL, Feldman T, Pedersen WR, Lim DS, Kipperman R, Smalling R, Bajwa T, Herrmann HC, Lasala J, Maddux JT, Tuzcu M, Kapadia S, Trento A, Siegel RJ, Foster E, Glower D, Mauri L, Kar S; EVEREST II Investigators. Acute and 12-month results with catheter-based mitral valve leaflet repair: the EVEREST II (Endovascular Valve Edge-to-Edge Repair) High Risk Study. J Am Coll Cardiol. 2012;59:130-9.

9. Feldman T, Kar S, Rinaldi M, Fail P, Hermiller J, Smalling R, Whitlow PL, Gray W, Low R, Herrmann HC, Lim S, Foster E, Glower D; EVEREST Investigators. Percutaneous mitral repair with the MitraClip system: safety and midterm durability in the initial EVEREST (Endovascular Valve Edge-to-Edge REpair Study) cohort. J Am Coll Cardiol. 2009;54:686-94.

10. Shanks M, Delgado V, Ng AC, van der Kley F, Schuijf JD, Boersma E, van de Veire NR, Nucifora G, Bertini M, de Roos A, Kroft L, Schalij MJ, Bax JJ. Mitral valve morphology assessment: three-dimensional transesophageal echocardiography versus computed tomography. Ann Thorac Surg. 2010;90:1922-9.

11. Rector TS, Kubo SH, Cohn JN. Validity of the Minnesota Living with Heart Failure questionnaire as a measure of therapeutic response to enalapril or placebo. Am J Cardiol. 1993;71: 1106-7.

12. Mauri L, Garg P, Massaro JM, Foster E, Glower D, Mehoudar P, Powell F, Komtebedde J, McDermott E, Feldman T. The EVEREST II Trial: design and rationale for a randomized study of the evalve mitraclip system compared with mitral valve surgery for mitral regurgitation. Am Heart J. 2010;160:23-9.

13. Lang RM, Bierig $M$, Devereux RB, Flachskampf FA, Foster E, Pellikka PA, Picard MH, Roman MJ, Seward J, Shanewise J, Solomon S, Spencer KT, St John Sutton M, Stewart W; American Society of Echocardiography's Nomenclature and Standards Committee; Task Force on Chamber Quantification; American College of Cardiology Echocardiography Committee; American Heart Association; European Association of
Echocardiography, European Society of Cardiology. Recommendations for chamber quantification. Eur $J$ Echocardiogr. 2006;7:79-108.

14. Zoghbi WA, Enriquez-Sarano M, Foster E, Grayburn PA, Kraft CD, Levine RA, Nihoyannopoulos P, Otto CM, Quinones MA, Rakowski H, Stewart WJ, Waggoner A, Weissman NJ; American Society of Echocardiography. Recommendations for evaluation of the severity of native valvular regurgitation with two-dimensional and Doppler echocardiography. J Am Soc Echocardiogr. 2003;16:777-802.

15. Salgo IS, Gorman JH 3rd, Gorman RC, Jackson BM, Bowen FW, Plappert T, St John Sutton MG, Edmunds LH Jr. Effect of annular shape on leaflet curvature in reducing mitral leaflet stress. Circulation. 2002;106:711-7.

16. Debonnaire P, Al Amri I, Leong DP, Joyce E, Katsanos S, Kamperidis V, Schalij MJ, Bax JJ, Marsan NA, Delgado V. Leaflet remodelling in functional mitral valve regurgitation: characteristics, determinants, and relation to regurgitation severity. Eur Heart J Cardiovasc Imaging. 2015;16:290-9.

17. Delgado V, Kapadia S, Marsan NA, Schalij MJ, Tuzcu EM, Bax JJ. Multimodality imaging before, during, and after percutaneous mitral valve repair. Heart. 2011;97:1704-14.

18. Greenhouse DG, Dellis SL, Schwartz CF, Loulmet DF, Yaffee DW, Galloway AC, Grossi EA. Regional changes in coaptation geometry after reduction annuloplasty for functional mitral regurgitation. Ann Thorac Surg. 2012;93:1876-80.

19. Schmidt FP, von Bardeleben RS, Nikolai P, Jabs A, Wunderlich N, Munzel T, Hink U, Warnholtz A. Immediate effect of the MitraClip procedure on mitral ring geometry in primary and secondary mitral regurgitation. Eur Heart $J$ Cardiovasc Imaging. 2013; $14: 851-7$

20. Altiok E, Hamada S, Brehmer K, Kuhr K, Reith S, Becker M, Schroder J, Almalla M, Lehmacher W, Marx N, Hoffmann R. Analysis of procedural effects of percutaneous edge-to-edge mitral valve repair by $2 \mathrm{D}$ and $3 \mathrm{D}$ echocardiography. Circ Cardiovasc Imaging. 2012;5:748-55.

21. Schueler R, Momcilovic D, Weber M, Welz A, Werner N, Mueller C, Ghanem A, Nickenig G, Hammerstingl C. Acute changes of mitral valve geometry during interventional edge-toedge repair with the MitraClip system are associated with midterm outcomes in patients with functional valve disease: preliminary results from a prospective single-center study. Circ Cardiovasc Interv. 2014;7:390-9.

22. Rim Y, Chandran KB, Laing ST, Kee P, McPherson DD, Kim H. Can Computational Simulation Quantitatively Determine Mitral Valve Abnormalities? JACC Cardiovasc Imaging. 2014 Nov 26. [Epub ahead of print]. 